\title{
UCHL1 Promotes Chemoresistance to 5-Fluoruracil Based Adjuvant Chemotherapy and is a Prognostic Marker for Stage II Colon Cancer Patients
}

\section{Liyuan Ma}

General Hospital of Ningxia Medical University

\section{Chaowen Wu}

Shenzhen Longhua District Central Hospital

\section{Lu Ding}

General Hospital of Ningxia Medical University

\section{Dong Yu}

General Hospital of Ningxia Medical University

\section{Xinrong Shi}

General Hospital of Ningxia Medical University

Jie Ning

Shenzhen Longhua District Central Hospital

\section{Zehua Wu}

The Affiliated Hospital of Qingdao University

Tao Jiang ( jtyy2021@126.com )

General Hospital of Ningxia Medical University https://orcid.org/0000-0003-0156-5428

\section{Research}

Keywords: UCHL1, Stage II colon cancer, Prognosis, Chemoresistance

Posted Date: May 24th, 2021

DOI: https://doi.org/10.21203/rs.3.rs-532218/v1

License: (c) (1) This work is licensed under a Creative Commons Attribution 4.0 International License. Read Full License 


\section{Abstract}

Background: 5-Fluoruracil based adjuvant chemotherapy after radical resection is recommended for stage II colon cancer patients with high risk of recurrence. Up to now, novel biomarkers still needed for better stratification for improving prognosis.

Methods: Here we report that UCHL1 is an independent prognostic factor for stage II colon cancer patients and promotes chemoresistance both in vitro and in vivo.

Results: Our study indicated that UCHL1 is significant up regulated in 96 pairs of stage II colon cancer patients who received postoperative 5-FU based chemotherapy. Stage II colon cancer patients with high UCHL1 expression showed high recurrence rate after chemotherapy. Multivariate Cox regression analysis showed that $\mathrm{UCHL} 1$ is an independent prognostic factor for overall survival $(P=0.008)$ and disease-free survival ( $P=0.001)$. 5-FU based chemoresistance is examined in colon cancer cell lines (RKO and LoVo) with down regulation of UCHL 1 by cytotoxicity test. Down regulation of UCHL1 exhibited decreased cell viability, elevated cell apoptosis rate, increased G2/M-phase and elevated level of cleaved caspase 3 and PARP when treated with 5-FU. Furthermore, the results in xenograft model are consistent with results in vitro.

Conclusions: UCHL1 potentially contributing to identify recurrence risk and predict the benefit for postoperative 5-FU based adjuvant chemotherapy in stage II colon cancer patients.

\section{Background}

Colon cancer remains a major cause of cancer-related deaths among the world. Despite recent improvements in the chemotherapies and multidisciplinary treatments in colon cancer the overall survival remains poor and its therapeutic efficacy is not ideal ${ }^{[1,2]}$. To estimate the prognosis of colon cancer patients, tumors are currently classified into stage I to IV according to the tumor-node-metastasis (TNM) staging, which is primarily based upon histopathological features of the tumor. 5-Fluoruracil based adjuvant chemotherapy after curative surgery is considered as standard therapy for stage II/III colon cancer $^{[3]}$. Approximately thirty percent of colon cancer patients are stage II patients in China which possess good overall 5 year prognosis. Because stage II colon cancer displays some different characteristics, less than $5 \%$ of patients benefit from postoperative chemotherapy, routine adjuvant chemotherapy for stage II colon cancer patients is often questionable ${ }^{[4-6]}$. Current National Comprehensive Cancer Network guidelines recommend adjuvant treatment limited to patients at high risk of recurrence identified by at least one of the following clinical characteristics: pT4 tumors, extramural vascular, lymphatic or perineural invasion, poorly differentiated histology, and obstruction or tumor perforation and lymph node sampling lower than twelve $\mathrm{e}^{[7]}$. Obviously, high-risk patients with stage II colon cancer may benefit from adjuvant chemotherapy, but additional prognostic markers still needed for better stratification. 
Mutations (both hereditary and somatic) that contribute to adenoma formation or progression have been identified in a number of genes. Most significantly, mutations in genes involved in Wnt/ $\beta$-catenin signaling, such as the adenomatous polyposis coli (APC) gene, cause colon cancer through the constitutive formation of a nuclear $\beta$-catenin/TCF transcription complex in colonic epithelial cells ${ }^{[8-10]}$.

Ubiquitin C-terminal hydrolase L1(UCHL1), also known as PARK5, belongs to the peptidase C12 family $[11$, 12]. UCHL1 acts as either an oncogene or a tumor-suppressor gene depending on the cancer types, partially because its nature of the deubiquitinating activity that inhibits proteasome mediated degradation is diverse, by the deubiquitination of proteins themselves that are affected in a variety of tumor tissues ${ }^{[13-15]}$. Previous report showed that UCHL1 promotes uterine serous cancer cell proliferation and cell cycle progression ${ }^{[16]}$. UCHL1 acts as a candidate oncoprotein that promotes TGF $\beta$ induced breast cancer metastasis and chemoresistance. Also, UCHL1 upregulation by verapamil enhanced the reversal effect of verapamil on chemoresistance of hepatocellular carcinoma and promoted cell apoptosis $^{[17,18]}$. Here, we examine the UCHL1 expression patterns and clarify the pathological significance and patients survival in stage II colon cancer. Then we evaluate the value of UCHL1 for predict response to 5-Fu based chemotherapy in stage II colon cancer, and determine whether UCHL1 expression is a useful marker for guiding individualized adjuvant chemotherapy after radical resection in stage II colon cancer patients.

\section{Materials And Methods}

\section{Patients and tissue samples}

A total of 96 tissue samples from stage II colon cancer patients with pathologically confirmed diagnosis were obtained immediately after surgery and frozen at $-80^{\circ} \mathrm{C}$ in liquid nitrogen before being deposited in the Shenzhen Longhua District Central Hospital from January 2019 to August 2019. All patients received 5-FU based chemotherapy after surgery and the pathologic verification of diagnosis and staging were summarized according to the National Comprehensive Cancer Network (NCCN) Practice guidelines. Overall survival (OS) and disease-free survival (DFS) were defined as the interval from the initial surgery to death and clinically recurrence or metastasis, respectively. Written informed consent was obtained from each patient before surgery and all study protocols were approved by the Ethics Committee for Clinical Research of Shenzhen Longhua District Central Hospital.

\section{Primers and qPCR}

Total RNA extraction of 96 pairs frozen stage II colon cancer tissues were performed according to the manufacturer's instructions (AllPrep DNA/RNA Mini Kit, Qiagen, Germany). First-strand cDNA was synthesized from 1 microgram of total RNA using the A3500 RT-PCR System (Promega, USA). qPCR was performed using LightCycler ${ }^{\circledR} 480$ SYBR Green I Master (Roche, USA) according to the manufacturer's protocol. For gene expression analysis, qPCR was performed by using sequence-specific primers for: UCHL1F: 5'-CCGAGATGCTGAACAAAG-3'. UCHL1R: 5'-CAGAGACTCCTCTTCCAG-3'. For internal primer, $\beta$ - 
actinF: 5'-CGGGAAATGTGCGTGAC-3' $\beta$-actinR: 5'-TGGAAGGTGGACAGCGAGG-3'. The relative UCHL1 mRNA expression was calculated using $2^{-\triangle} \triangle \mathrm{Ct}$ comparative method.

3 Immunohistochemistry

A total of 114 stage II colon cancer specimens were collected, fixed in 10\% neutral buffer formalin, and embedded in paraffin blocks. Tissue sections $(4 \mu \mathrm{m})$ were processed for immunohistochemical staining according to the Dako Envision System (Dako Glostrup, Denmark). Briefly, the sections were deparaffinized, rehydrated in serially graded ethanol, and heated 5 min in citric buffer ( $\mathrm{pH} 6.0$ ) once for antigen retrieval. Sections were immunolabeled with primary antibody UCHL1(1:200 dilution, ab27053, United Kingdom) at $4{ }^{\circ} \mathrm{C}$ overnight. Washed sections were incubated with goat anti-rabbit Envision System Plus-HRP (Dako Glostrup, Denmark). PBS was used as a negative control. Immunostaining scores were finally recorded by two experienced pathologists in a blinded fashion according to the staining intensity and extent of staining which was previously described ${ }^{[19]}$.

4 Western blot analysis

Total protein of frozen colon cancer and its paired normal mucosa specimens were extracted and lysed in RIPA buffer with protease inhibitors. Each $50 \mu \mathrm{g}$ aliquot of total protein were separated via $8 \%$ SDS-PAGE and transferred to nitrocellulose membrane. The membranes were blocked in $10 \%$ skim milk and incubated overnight with anti-UCHL1 (1:500 dilution, ab27053, United Kingdom). For in vitro experiments, Cell lysates were separated via $8 \%$ SDS-PAGE and transferred to nitrocellulose membrane. The membranes were blocked in $10 \%$ skim milk and incubated overnight with anti-cleaved Caspase-3, anticleaved PARP. Subsequently, all membranes were incubated for $1 \mathrm{~h}$ with horseradish peroxidaseconjugated secondary antibody, and the specific bands were collected finally.

5 Cell culture and lentivirus infection

The high expression of UCHL1 in RKO and LoVo colon cancer cell lines was observed in our previous study, so we choose these two cell lines for further functional tests. RKO and LoVo were purchased from American Type Culture Collextion (ATCC ${ }^{\circledR}$ Manassas, VA, USA). All cells were maintained in Dulbecco's modified Eagle's medium supplemented with $10 \%$ fetal bovine serum (Invitrogen Corp, USA) and cells were incubated at $37^{\circ} \mathrm{C}$ in a humidified incubator containing 5\% CO2. 5-FU was purchased from Sigma (St Louis, MO, USA). Lentiviral plasmid for down regulation UCHL1 and plasmid for negative control were constructed by Genechem Co. Ltd. (Shanghai, China). The specific siRNA sequence for UCHL1:CCGGGTGTGAGCTTCAGATGGTGAACTCGAGTTCAC

CATCTGAAGCTCACACTTTTT. In brief, the lentiviruses were produced by transfecting 293T cells with pGC-LV, pHelper 1.0 and pHelper 2.0 plasmids mix and lipofectamine-3000 (Invitrogen, NY) in Opti-MEM medium (Gibco, USA). RKO and LoVo cells were transduced with $5 \times 10^{5}$ transducing units $/ \mathrm{mL}$ of lentivirus particles. Knockdown efficiency higher than $80 \%$ was considered acceptable. 
To analyze the viability of cells treated with different concentrations of 5 -FU $(0,0.5,1,5,10,50 \mu \mathrm{mol} / \mathrm{L})$, $2 \times 10^{3}$ cells / well were seeded in 96-well plates. Then, $10 \mu \mathrm{L}$ of CCK-8 solution (Sigma, St Louis, MO, USA) were added to each well after sixty hours. The 450nm absorbance of each well was determined on a microplate reader (Bio-Rad, USA). Cell viability was calculated according to the following formula: Cell viability $(\%)=$ A450 (test group) / A450 (control group) ×100\%. IC50 (half maximal inhibitory concentration) was calculated from the dose - response curves.

7 Cell apoptosis and cell cycle

The Annexin V-PE and 7-AAD (BD Biosciences, USA) double staining method was used to examine apoptosis and cell cycle. The frequency of apoptosis was measured using the BD FACSCaliburTM Flow Cytometer (BD Biosciences, USA) according to the manufacturer's instructions. Before assessing the chemosensitivity of colon cancer cells to 5-fluorouracil, the optimal drug concentration of 5-FU inducing cell death was determined on untransfected cells. Cells were treated with 5-FU (SIGMA, USA) at a final concentration of $10 \mu \mathrm{M}$ for 48 hours. The percentage of 5-FU-treated and untreated apoptotic cells were calculated according to the number of cells positive or negative for Annexin V-PE and 7-AAD. Results are presented as the percentage of total cells that were living cells (Ann-/7-AAD-), early apoptotic cells (Ann+/7-AAD-), late apoptotic cells, and dead cells (Ann+/7-AAD +). In addition, cell cycly procedures were conducted in accordance with the manufacture's instructions.

8 Xenografted tumor model

Twenty four 4-week- BALB/c male nude mice were purchased from the Institute of Zoology, Chinese Academy of Sciences of Shanghai and maintained in specific pathogen-free (SPF) conditions. Approximately $5 \times 10^{6}$ RKO cells transfected with siR-UCHL1 or negative control were injected subcutaneously into the opposite flanks of each mouse. When the tumor volumes were approximately $0.2 \mathrm{~cm}^{3}$, a dose of $20 \mathrm{mg} / \mathrm{kg} /$ day 5 -FU was applied for intraperitoneal injection twice a week, total 3 weeks. Tumor dimensions were measured once 5 days. All nude mice were sacrificed after 3 weeks. Tumor volume was calculated using the following formula: width ${ }^{2} \times$ length $\times 0.5$. All of the animal procedures were conducted in accordance with the Shenzhen Longhua District Central Hospital Animal Care guidelines.

\section{Results}

\section{Aberrant overexpression of UCHL1 in stage II colon cancer patients}

A total of 96 stage II colon cancer tissues were used to analysis UCHL1 mRNA expression. Randomly selected 4 paired stage II colon cancer tissues were used to analysis UCHL1 protein expression. As shown 
in Fig. 1A, the relative level of UCHL1 was significant up regulated in 96 stage II colon cancer tissues than in the matched non-cancerous mucosa $(P<0.001)$. Subsequent western blotting confirmed that the level of UCHL1 protein were also higher in the colon cancer tissues than in the paired non-cancerous mucosa (Fig. 1B).

\section{Correlation between UCHL1 expression and clinicopathological characteristics of colon cancer}

To further explore the correlation between UCHL1 and progression of colon cancer, UCHL1 expression patterns were determined by immunohistochemistry study in 114 stage II patients who accepted 5-FU based chemotherapy after radical resection. Results showed that the immunoreactive patterns of UCHL1 was predominantly positively identified in the majority of colon cancer specimens (Fig. 2A, Table 1). Of the 114 subjects, correlation between UCHL 1 expression and clinicopathological characteristics were demonstrated in Table 1. We observed that the overexpression of UCHL1 was closely correlated with depth of tumor invasion $(P=0.010)$, histologic differentiation $(P=0.001)$ and recurrence $(P<0.001)$. No correlations founds between UCHL1 expression and age, gender or tumor location status. Collectively, all these results indicated that UCHL1 possible plays critical role in stage II colon cancer patients.

\section{Overexpression of UCHL11 associated with a poor prognosis in stage II colon cancer}

To assess the clinical value of UCHL1 expression in stage II colon cancer patients survival, Kaplan-Meier curves with a log rank test for overall survival (OS) and disease-free survival (DFS) were undertaken. The results indicated that there was a significant difference between UCHL1-positive and UCHL1-negative groups who developed primary colon cancer recurrence after 5-FU based chemotherapy. The recurrence rate was correlated with UCHL1 expression status, positive UCHL1 expression were associated with increased risk of recurrence $(P=0.001)$. As shown in Fig. 2B, patients with UCHL1-positive (weak and strong) expression had a remarkably lower OS and DFS rate than patients with UCHL1-negative expression $(P<0.001)$. The estimated mean OS time was significantly different between patients with UCHL1-positive and UCHL1-negative tumors (37.29 \pm 19.225 and $54.12 \pm 10.982$ months, respectively, $P<$ 0.001). The estimated mean DFS time was $33.21 \pm 17.432$ and $50.014 \pm 14.352$ months for subjects with UCHL1-positive and UCHL1-negative tumors $(P<0.001)$. In addition, univariate and multivariate hazard ratios for survival were calculated by Cox proportional hazards model analyses. In multivariate analysis using the clinicopathological variables such as $\mathrm{T}$ stage and differentiation grade, the expression of UCHL1 was an independent prognostic marker to predict patient outcomes (OS: hazard ratio: 3.504, 95\% confidence interval: $2.246-6.807, P=0.008$. DFS: hazard ratio: $2.304,95 \%$ confidence interval: $1.967-$ 6.383, $P=0.001$, respectively (Table 2 and Table 3 ).

\section{Down regulation of UCHL1 inhibits cell viability and chemoresistance in vitro}

Chemoresistance is one of the important causes of failed therapy and results in recurrence in colon cancer patients. To determine the potential role of UCHL1 in chemoresistance, a lentiviral vector for inhibition UCHL 1 gene were constructed and transfected in RKO and LoVo colon cancer cell lines. All experimental groups exposed to different concentrations of 5-FU treatment in vitro. CCK8 test indicated 
that down regulation of UCHL1 significantly inhibited cell viability of RKO and LoVo cells (Fig. 3A). The IC50 were significant decreased in RKO and LoVo cells (Fig. 3B).

\section{Down regulation of UCHL1 sensitizes colon cancer cells to apoptosis}

To further determine the potential function of UCHL1 in chemoresistance, cell cycle and apoptosis analysis were applied. Down regulation of UCHL1 showed a significant increase in G2/M-phase cells, and a reciprocal decrease in G0/G1-phase cells, compared to vector cells (Fig. 4A). The results we observed are augmented by the addition of 5-FU. These findings indicated that at the time of 5-FU treatment, cells are blocked in a more chemosensitive stage of cell cycle. In addition, down regulation of UCHL1 had little effects on cell viability in the absence of 5-FU. However, the ability to promote cell apoptosis were observed when cells treated with 5-FU (Fig. 4B, 4C). To further explore the molecular mechanisms underlying the anti-apoptotic role of UCHL1, we analyzed two biomarkers of apoptosis, poly adenosine diphosphate ribose polymerase (PARP) and cleaved caspase 3. After 48 hours treatment with $10 \mu \mathrm{M} 5$-FU, cleaved PARP and caspase 3 were detected in the siR-UCHL1 cell lines (Fig. 5). Compared with control cells, which were resistant to apoptosis, the majority of PARP and caspase 3 proteins were uncleaved and remained full length. All in vitro findings showed that UCHL1 plays important roles in protect colon cancer cells from 5-FU induced apoptosis.

\section{Down regulation of UCHL1 can inhibit colon cancer growth and enhance 5-FU based chemotherapy sensitivity in vivo.}

To evaluate the effect of UCHL1 on tumorigenesis in vivo, RKO cells were subcutaneously implanted in $\mathrm{BALB} / \mathrm{c}$ mice. Cells transfected with the siR-UCHL1 or Vector control were injected into the opposite flanks of each animal which were treated with 5-FU or not. The mice were euthanized and the tumor growth curve and harvested tumor weights were shown in Fig. 6. Down regulation of UCHL1 results in significantly reduced average tumor size and weight compared to that of control tumors. An even more significant reduction was indicated in the siR-UCHL1 group treated with 5-FU. Taken together, these findings confirmed that down regulation of UCHL1 can inhibit colon cancer progress and enhance 5-FU based chemotherapy sensitivity in vivo.

\section{Discussion}

Colon cancer is one of the major malignant diseases detrimental to health and chemotherapy resistanceis hot researched topic at present ${ }^{[20,21]}$. Our study support the hypothesis that UCHL1 could serve as a prognostic indicator of stage II colon cancer patients who treated with 5-fluorouracil based adjuvant chemotherapy following curative surgery. Moreover, we investigated the impact of UCHL1 inhibition on chemoresistance in colon cancer cells. We clearly showed that UCHL1 inhibition confers a better phenotype and improved 5-FU based chemosensitivity in colon cancer cells.

UCHL1 is a widely studied deubiquitinase as it has been described in both neurodegenerative disorders and varying malignancies ${ }^{[22,23]}$. Depending on tumor types, some studies report $U C H L 1$ as an oncogene, 
whereas others discuss its role as a tumor suppressor gene as a result of $\mathrm{CpG}$ island methylation ${ }^{[24]}$. Previous report showed that UCHL1 acts as a candidate oncoprotein that promotes TGF $\beta$ induced breast cancer metastasis and chemoresistance. Inhibition of UCHL1 offer potential forms of treatment for invasive carcinomas including EBV-positive malignancies ${ }^{[25]}$. Based on the previous study, we further revealed that UCHL1-positive expression associated with poor prognosis in stage II colon cancer patients, and down regulation of UCHL 1 could inhibit 5-FU based chemoresistance and sensitize colon cancer cells to apoptosis. These findings showed that UCHL1 promote the biological activities of stage II colon cancer patients after surgery, even though treated with 5-FU based chemotherapy.

Up to now, the partial value of adjuvant chemotherapy for stage II colon cancer patients remains controversial. Stage II colon cancer patients were considered for chemotherapeutic therapy if, based on clinical and pathological evaluation, they are deemed to be at a high risk of relapse ${ }^{[26-28]}$. NCCN Guidelines indicated that patients of stage II with high risk factors, such as poor histological type, few examined lymph nodes, intestinal obstruction and vascular invasion, are likely to specifically benefit from chemotherapy ${ }^{[29]}$. In our present research, stage II patients with UCHL1-positive expression showed increased risk of tumor recurrence when treated with 5-FU after radical operation. In addition, patients with UCHL1-positive expression had a remarkably lower OS and DFS rate, was an independent prognostic marker to predict patient outcomes. Our data showed that UCHL1 possess potential to predict 5-FU susceptibility in patients with stage II. These information could helpful for identify target therapeutics to patient subgroups with highest risk for disease recurrence.

5-FU based chemotherapy, was previously approved for first or second line treatment of patients with colon cancer. Capecitabine is widely used in the therapy of stage II colon cancer patients, which is an oral drug of Fluorouracil (FU) ${ }^{[27]}$. 5-FU induced cancer cells apoptosis throuth DNA damage and growth inhibition. Chemotherapy resistance could result from multiple factors, including enhanced drug inactivation, mutation of drug target and defects of mismatch repair genes [30, 31]. Our data showed that down regulation of UCHL1 significantly inhibited cell viability of RKO and LoVo cells, the IC50 of RKO and LoVo cells were significantly decreased by UCHL1 inhibition. Therefore, down regulation of UCHL1 could contribute to chemosensitivity of 5-FU based thermotherapy. Moreover, down regulation of UCHL1 resulted in cellular arrest in G2-M stage, a more chemosensitive stage of cell cycle. So, cells were arrested at a more chemosensitive stage of cell cycle. Molecular biology of tumors revealed that the imbalanced cell proliferation and cell apoptosis is an important mechanism of the tumorigenesis and progression ${ }^{[32-}$ 34]. In our study, UCHL1 inhibition significantly increased the extent of 5-FU induced apoptosis of colon cancer cells. To further explore the mechanism by which UCHL1 mediates chemoresistance, we examined two apoptosis markers, PARP and caspase 3 cleavage ${ }^{[35]}$. In UCHL1 down regulation cells treated with 5FU, significantly more cleaved PARP and caspase 3 were detected compared with control cells. These findings showed that UCHL1 could confer chemoresistance through anti-apoptotic pathways. Further in vivo study indicated that tumor growth and weights were significantly decreased in UCHL1 inhibition tumor xenografts, especially when treated with 5-FU. These results were consistent with previous in vitro results and suggest that UCHL1 is a critical protein responsible for 5-FU based chemoresistance. 
In conclusion, UCHL1 can be used to effectively evaluate and distinguish recurrent risk in stage II colon cancer patients. UCHL1 abnormal expression decreases 5-FU susceptibility in colon cancer cells, which could contribute for guiding individualized chemotherapy benefit in stage II colon cancer patients after complete mesocolic excision, CME radical operation.

\section{Conclusions}

UCHL1 potentially contributing to identify recurrence risk and predict the benefit for postoperative 5-FU based adjuvant chemotherapy in stage II colon cancer patients.

\section{Declarations}

\section{Acknowledgements}

None.

\section{Funding}

The project was supported by: (1) Scientific Research Project grant funded by Ningxia High School (NGY2018-76). (2) National Natural Science Foundation of China (81602083). (3) Government-funded personnel studying abroad Innovation entrepreneur project funded by Department of Human Resources and Social Security of Ningxia. (4) Natural Science Foundation of Ningxia (2020AAC03402, 2020AAC03401, 2018AAC03131). (5) Ningxia Medical University Scientific Research Project (XZ2019006, XY201822).

\section{Availability of data and materials}

The data that support the findings of this study are available from the corresponding author upon reasonable request.

\section{Author' contributions}

Liyuan Ma, Dong Yu, Xinrong Shi and Zehua Wu conceived and designed the experiments. Lu Ding, Jie Ning and Chaowen Wu analyzed the data. Liyuan Ma and Tao Jiang wrote the manuscript. All authors read and approved the manuscript and agree to be accountable for all aspects of the research in ensuring that the accuracy or integrity of and part of the work are appropriately investigated and resolved.

\section{Competing interests}

The authors declare that they have no competing interests.

\section{Consent for publication}

Not applicable. 


\section{Ethics approval and consent to participate}

Written informed consent was obtained from each patient before surgery and all study protocols were approved by the Ethics Committee for Clinical Research of Shenzhen Longhua District Central Hospital. All of the animal procedures were conducted in accordance with the Shenzhen Longhua District Central Hospital Animal Care guidelines

\section{References}

1. Kong X, Chen J, Xie W, Brown SM, Cai Y, Wu K, Fan D, Nie Y, Yegnasubramanian S, Tiedemann RL, Tao Y, Chiu Yen RW, Topper MJ, Zahnow CA, Easwaran H, Rothbart SB, Xia L, Baylin SB. Defining uhrf1 domains that support maintenance of human colon cancer DNA methylation and oncogenic properties. Cancer cell. 2019;35:633-48. e637.

2. Ruland J. Colon cancer: Epithelial notch signaling recruits neutrophils to drive metastasis. Cancer cell. 2019;36:213-4.

3. Fields AC, Lu P, Goldberg J, Irani J, Bleday R, Melnitchouk N. The role of adjuvant chemotherapy in stage ii and iii mucinous colon cancer. Journal of surgical oncology 2019.

4. Arredondo J, Simo V, Castanon C, Suarez MJ, Alvarez MC. Complete pathologic response after neoadjuvant chemotherapy in locally advanced colon cancer. Cirugia espanola 2019.

5. Gao Y, Liu Z, Ding Z, Hou S, Li J, Jiang K. Microrna-155 increases colon cancer chemoresistance to cisplatin by targeting forkhead box 03. Oncology letters. 2018;15:4781-8.

6. Li Q, Chen Y, Zhang D, Grossman J, Li L, Khurana N, Jiang H, Grierson P, Herndon J, DeNardo DG, Challen GA, Liu J, Ruzinova MB, Fields RC, Lim KH. Irak4 mediates colitis-induced tumorigenesis and chemoresistance in colon cancer. JCl insight 2019.

7. Meyers BM, Cosby R, Quereshy F, Jonker D. Adjuvant systemic chemotherapy for stages ii and iii colon cancer after complete resection: A clinical practice guideline. Current oncology. 2016;23:41824.

8. Dupasquier S, Blache P, Picque Lasorsa L, Zhao H, Abraham JD, Haigh JJ, Ychou M, Prevostel C. Modulating pkcalpha activity to target wnt/beta-catenin signaling in colon cancer. Cancers 2019;11.

9. Souris JS, Zhang HJ, Dougherty U, Chen NT, Waller JV, Lo LW, Hart J, Chen CT, Bissonnette M. A novel mouse model of sporadic colon cancer induced by combination of conditional apc genes and chemical carcinogen in the absence of cre recombinase. Carcinogenesis 2019.

10. Ye K, Xu C, Hui T. Mir-34b inhibits the proliferation and promotes apoptosis in colon cancer cells by targeting wnt/beta-catenin signaling pathway. Bioscience reports 2019.

11. Gu Y, Ding X, Huang J, Xue M, Zhang J, Wang Q, Yu H, Wang Y, Zhao F, Wang H, Jin M, Wu Y, Zhang Y. 'The Deubiquitinating Enzyme Uchl1 Negatively Regulates the Immunosuppressive Capacity and Survival of Multipotent Mesenchymal Stromal Cells'. Cell Death Dis. 2018;9:459.

12. Gu Y, Lv F, Xue M, Chen K, Cheng C, Ding X, Jin M, Xu G, Zhang Y, Wu Z, Zheng L, Wu Y. 'The Deubiquitinating Enzyme Uchl1 Is a Favorable Prognostic Marker in Neuroblastoma as It Promotes 
Neuronal Differentiation'. J Exp Clin Cancer Res. 2018;37:258.

13. Liu H, Povysheva N, Rose ME, Mi Z, Banton JS, Li W, Chen F, Reay DP, Barrionuevo G, Zhang F. and S. H. Graham, 'Role of Uchl1 in Axonal Injury and Functional Recovery after Cerebral Ischemia'. Proc Natl Acad Sci U S A. 2019;116:4643-50.

14. Moore MD, Finnerty B, Gray KD, Hoda R, Liu YF, Soong L, Beninato T, Rao R, Zarnegar R, Fahey TJ, 3rd, 'Decreased Uchl1 Expression as a Cytologic Biomarker for Aggressive Behavior in Pancreatic Neuroendocrine Tumors', Surgery, 163 (2018), 226 - 31.

15. Xu Y, Gao H, Hu Y, Fang Y, Qi C, Huang J, Cai X, Wu H, Ding X, Zhang Z. 'High Glucose-Induced Apoptosis and Necroptosis in Podocytes Is Regulated by Uchl1 Via Ripk1/Ripk3 Pathway'. Exp Cell Res. 2019;382:111463.

16. Kwan SY, Au-Yeung CL, Yeung TL, Rynne-Vidal A, Wong KK, Risinger JI, Lin HK, Schmandt RE, Yates MS, Mok SC, Lu KH, 'Ubiquitin Carboxyl-Terminal Hydrolase L1 (Uchl1) Promotes Uterine Serous Cancer Cell Proliferation and Cell Cycle Progression', Cancers (Basel), 12 (2020).

17. Liu S, Gonzalez-Prieto R, Zhang M, Geurink PP, Kooij R, lyengar PV, van Dinther M, Bos E, Zhang X, Le Devedec SE, van de Water B, Koning RI, Zhu HJ, Mesker WE, Vertegaal ACO, Ovaa H, Zhang L, Martens JWM. and P. Ten Dijke, 'Deubiquitinase Activity Profiling Identifies Uchl1 as a Candidate Oncoprotein That Promotes Tgfbeta-Induced Breast Cancer Metastasis', Clin Cancer Res (2019).

18. Yang G, Fan G, Zhang T, Ma K, Huang J, Liu M, Teng X, Xu K, Fan P, Cheng D. 'Upregulation of Ubiquitin Carboxyl-Terminal Hydrolase L1 (Uchl1) Mediates the Reversal Effect of Verapamil on Chemo-Resistance to Adriamycin of Hepatocellular Carcinoma'. Med Sci Monit. 2018;24:2072-82.

19. Jiang T, Yang C, Ma L, Wu Z, Ye L, Ma X, Li H, Fan J, Yang Y. 'Overexpression of Grk3, Promoting Tumor Proliferation, Is Predictive of Poor Prognosis in Colon Cancer'. Dis Markers. 2017;2017:1202710.

20. Boyne DJ, Cuthbert CA, O'Sullivan DE, Sajobi TT, Hilsden RJ, Friedenreich CM, Cheung WY, Brenner DR. 'Association between Adjuvant Chemotherapy Duration and Survival among Patients with Stage li and lii Colon Cancer: A Systematic Review and Meta-Analysis'. JAMA Netw Open. 2019;2:e194154.

21. Zhang C, Yin S, Tan Y, Huang J, Wang P, Hou W, Zhang Z, Xu H. 'Patient Selection for Adjuvant Chemotherapy in High-Risk Stage li Colon Cancer: A Systematic Review and Meta-Analysis', Am J Clin Oncol (2020).

22. Cheng W, Chen YL, Wu L, Miao B, Yin Q, Wang JF, Fu ZJ. 'Inhibition of Spinal Uchl1 Attenuates Pain Facilitation in a Cancer-Induced Bone Pain Model by Inhibiting Ubiquitin and Glial Activation'. Am J Transl Res. 2016;8:3041-8.

23. Nakashima R, Goto Y, Koyasu S, Kobayashi M, Morinibu A, Yoshimura M, Hiraoka M, Hammond EM, Harada H. 'Uchl1-Hif-1 Axis-Mediated Antioxidant Property of Cancer Cells as a Therapeutic Target for Radiosensitization'. Sci Rep. 2017;7:6879.

24. Trifa F, Karray-Chouayekh S, Jmaa ZB, Jmal E, Khabir A, Sellami-Boudawara T, Frikha M, Daoud J, Mokdad-Gargouri R. 'Frequent Cpg Methylation of Ubiquitin Carboxyl-Terminal Hydrolase 1 (Uchl1) in 
Sporadic and Hereditary Tunisian Breast Cancer Patients: Clinical Significance'. Med Oncol. 2013;30:418.

25. Kobayashi E, Hwang D, Bheda-Malge A, Whitehurst CB, Kabanov AV, Kondo S, Aga M, Yoshizaki T, Pagano JS, Sokolsky M, Shakelford J. 'Inhibition of Uch-L1 Deubiquitinating Activity with Two Forms of Ldn-57444 Has Anti-Invasive Effects in Metastatic Carcinoma Cells', Int J Mol Sci, 20 (2019).

26. Yang $Y$, Yang $Y$, Yang H, Wang F, Wang H, Chen Q, Liu Y, Li A, Zhang Q. Adjuvant chemotherapy for stage ii colon cancer: Who really needs it. Cancer management research. 2018;10:2509-20.

27. Lee KY, Park JW, Lee KY, Cho S, Kwon YH, Kim MJ, Ryoo SB, Jeong SY, Park KJ. Oncologic outcomes after adjuvant chemotherapy with capecitabine compared to 5 -fluorouracil/leucovorin for geriatric stage ii colon cancer: A retrospective cohort study. Int J Colorectal Dis. 2019;34:629-39.

28. Fu J, Wu L, Ge C, Xu T, Li D, Fu W, Wang L, Du J. De-escalating chemotherapy for stage ii colon cancer? Therapeutic advances in gastroenterology. 2019;12:1756284819867553.

29. Benson AB, Venook AP, Al-Hawary MM, Cederquist L, Chen YJ, Ciombor KK, Cohen S, Cooper HS, Deming D, Engstrom PF, Garrido-Laguna I, Grem JL, Grothey A, Hochster HS, Hoffe S, Hunt S, Kamel A, Kirilcuk N, Krishnamurthi S, Messersmith WA, Meyerhardt J, Miller ED, Mulcahy MF, Murphy JD, Nurkin S, Saltz L, Sharma S, Shibata D, Skibber JM, Sofocleous CT, Stoffel EM, Stotsky-Himelfarb E, Willett CG, Wuthrick E, Gregory KM, Freedman-Cass DA. Nccn guidelines insights: Colon cancer, version 2.2018. Journal of the National Comprehensive Cancer Network: JNCCN. 2018;16:359-69.

30. Pokhriyal R, Hariprasad R, Kumar L, Hariprasad G. Chemotherapy resistance in advanced ovarian cancer patients. Biomark Cancer. 2019;11:1179299X19860815.

31. Riganti C, Contino M. New strategies to overcome resistance to chemotherapy and immune system in cancer. International journal of molecular sciences 2019;20.

32. Minassian LM, Cotechini T, Huitema E, Graham CH. Hypoxia-induced resistance to chemotherapy in cancer. Adv Exp Med Biol. 2019;1136:123-39.

33. Fearon ER. Molecular genetics of colorectal cancer. Annual review of pathology. 2011;6:479-507.

34. Colak S, Medema JP. 'Human Colonic Fibroblasts Regulate Stemness and Chemotherapy Resistance of Colon Cancer Stem Cells'. Cell Cycle. 2016;15:1531-7.

35. Larsen BD, Sorensen CS. The caspase-activated dnase: Apoptosis and beyond. FEBS J. 2017;284:1160-70.

\section{Tables}

Table l: Associations of UCHL1 expression with clinicopathological features in stage II colon cancer patients $(n=114)$ 


\begin{tabular}{|c|c|c|c|c|c|}
\hline \multirow[t]{2}{*}{ Variables } & \multirow[t]{2}{*}{$n=114$} & \multicolumn{4}{|c|}{ UCHL1 expression } \\
\hline & & Negative $(n=38)$ & Weak $(n=47)$ & Strong $(n=29)$ & $P$ value vvaValue ${ }^{\star}$ \\
\hline \multicolumn{6}{|l|}{ Age } \\
\hline$<60$ & 49 & 16 & 19 & 14 & 0.791 \\
\hline$\geq 60$ & 65 & 22 & 28 & 15 & \\
\hline \multicolumn{6}{|l|}{ Gender } \\
\hline Male & 69 & 20 & 31 & 18 & 0.449 \\
\hline Female & 45 & 18 & 16 & 11 & \\
\hline \multicolumn{6}{|l|}{ Location } \\
\hline Right & 42 & 16 & 17 & 9 & 0.643 \\
\hline Left & 72 & 22 & 30 & 20 & \\
\hline \multicolumn{6}{|l|}{ T Stage } \\
\hline T3 & 45 & 20 & 20 & 5 & $0.010^{\star}$ \\
\hline $\mathrm{T} 4$ & 69 & 18 & 27 & 24 & \\
\hline \multicolumn{6}{|c|}{ Differentiation } \\
\hline High & 48 & 25 & 15 & 8 & $0.001 *$ \\
\hline Low & 66 & 13 & 32 & 21 & \\
\hline \multicolumn{6}{|c|}{ Recurrence } \\
\hline No & 73 & 35 & 29 & 9 & $<0.001 *$ \\
\hline Yes & 41 & 3 & 18 & 20 & \\
\hline
\end{tabular}

$P$ values are based by Chi-square and Fisher's exact test. *Significant associations between 2 categorical variables.

Table II: Cox proportional hazards model univariate and multivariate analyses of individual parameters for correlations with overall survival (OS). 


\begin{tabular}{|c|c|c|c|c|c|c|}
\hline \multirow[t]{2}{*}{ Variable } & \multicolumn{3}{|c|}{ Univariate analysis } & \multicolumn{3}{|c|}{ Multivariate analysis } \\
\hline & HR & $\mathrm{Cl}(95 \%)$ & $P$ value* & HR & $\mathrm{Cl}(95 \%)$ & $P$ value ${ }^{\star}$ \\
\hline \multicolumn{7}{|l|}{ Age } \\
\hline$<60$ years & - & & & & & \\
\hline$\geq 60$ years & 1.574 & $0.698-1.876$ & 0.073 & & & \\
\hline \multicolumn{7}{|l|}{ Gender } \\
\hline Male & - & & & & & \\
\hline Female & 1.030 & $0.677-1.644$ & 0.793 & & & \\
\hline \multicolumn{7}{|l|}{ Location } \\
\hline Right & - & & & & & \\
\hline Left & 1.621 & $0.495-2.721$ & 0.062 & & & \\
\hline \multicolumn{7}{|l|}{ T stage } \\
\hline T3 & - & & & - & & \\
\hline T4 & 2.052 & $1.331-5.565$ & $0.021^{*}$ & 2.415 & $1.176-4.623$ & $0.008^{*}$ \\
\hline \multicolumn{7}{|l|}{ Differentiation } \\
\hline Well and Moderate & - & & & - & & \\
\hline Poor & 1.975 & $1.769-3.332$ & $0.041^{\star}$ & 1.848 & $1.342-3.827$ & $0.035^{\star}$ \\
\hline \multicolumn{7}{|l|}{ Recurrence } \\
\hline No & - & & & - & & \\
\hline Yes & 3.442 & $2.431-6.718$ & $0.001^{\star}$ & 3.525 & $2.961-6.003$ & $0.014^{\star}$ \\
\hline \multicolumn{7}{|l|}{ UCHL1 expression } \\
\hline Negative & - & & & - & & \\
\hline Weak and Strong & 3.012 & $2.305-7.023$ & $0.001^{\star}$ & 3.504 & $2.246-6.807$ & $0.008^{*}$ \\
\hline
\end{tabular}

HR: hazard radio, Cl: confidence interval.

Table III: Cox proportional hazards model univariate and multivariate analyses of individual parameters for correlations with overall survival (DFS). 


\begin{tabular}{|c|c|c|c|c|c|c|}
\hline \multirow[t]{2}{*}{ Variable } & \multicolumn{3}{|c|}{ Univariate analysis } & \multicolumn{3}{|c|}{ Multivariate analysis } \\
\hline & HR & $\mathrm{Cl}(95 \%)$ & $P$ value & HR & $\mathrm{Cl}(95 \%)$ & $P$ value ${ }^{\star}$ \\
\hline \multicolumn{7}{|l|}{ Age } \\
\hline$<60$ years & - & & & & & \\
\hline$\geq 60$ years & 1.398 & $0.213-1.902$ & 0.123 & & & \\
\hline \multicolumn{7}{|l|}{ Gender } \\
\hline Male & - & & & & & \\
\hline Female & 1.080 & $0.367-1.403$ & 0.684 & & & \\
\hline \multicolumn{7}{|l|}{ Location } \\
\hline Right & - & & & & & \\
\hline Left & 1.552 & $0.175-1.811$ & 0.102 & & & \\
\hline \multicolumn{7}{|l|}{ T stage } \\
\hline T3 & - & & & - & & \\
\hline $\mathrm{T} 4$ & 2.107 & $1.127-4.035$ & $0.041^{\star}$ & 1.967 & $1.703-3.993$ & $0.023^{\star}$ \\
\hline \multicolumn{7}{|l|}{ Differentiation } \\
\hline Well and Moderate & - & & & - & & \\
\hline Poor & 2.012 & $1.909-3.323$ & $0.030^{*}$ & 1.922 & $1.763-3.608$ & $0.041^{*}$ \\
\hline \multicolumn{7}{|l|}{ Recurrence } \\
\hline No & - & & & - & & \\
\hline Yes & 2.312 & $1.698-5.823$ & $0.040^{\star}$ & 2.378 & $1.847-6.002$ & $0.015^{\star}$ \\
\hline \multicolumn{7}{|l|}{ UCHL1 expression } \\
\hline Negative & - & & & - & & \\
\hline Weak and Strong & 2.912 & $2.245-6.697$ & $0.001 *$ & 2.304 & $1.967-6.383$ & $0.001 *$ \\
\hline
\end{tabular}

HR: hazard radio, Cl: confidence interval.

\section{Figures}




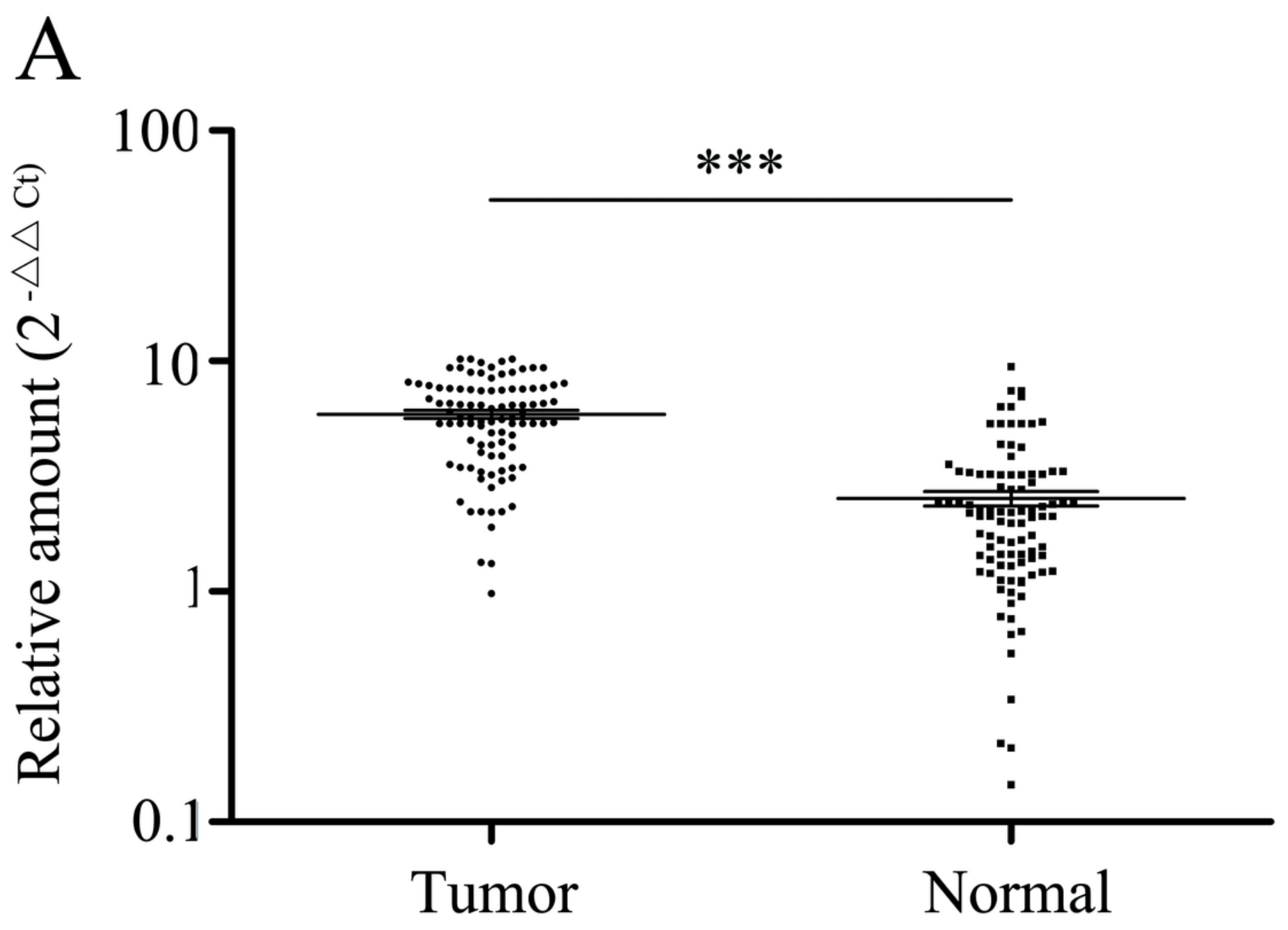

$\mathrm{B}$

$\begin{array}{llllllll}\mathrm{T} 1 & \mathrm{~N} 1 & \mathrm{~T} 2 & \mathrm{~N} 2 & \mathrm{~T} 3 & \mathrm{~N} 3 & \mathrm{~T} 4 & \mathrm{~N} 4\end{array}$

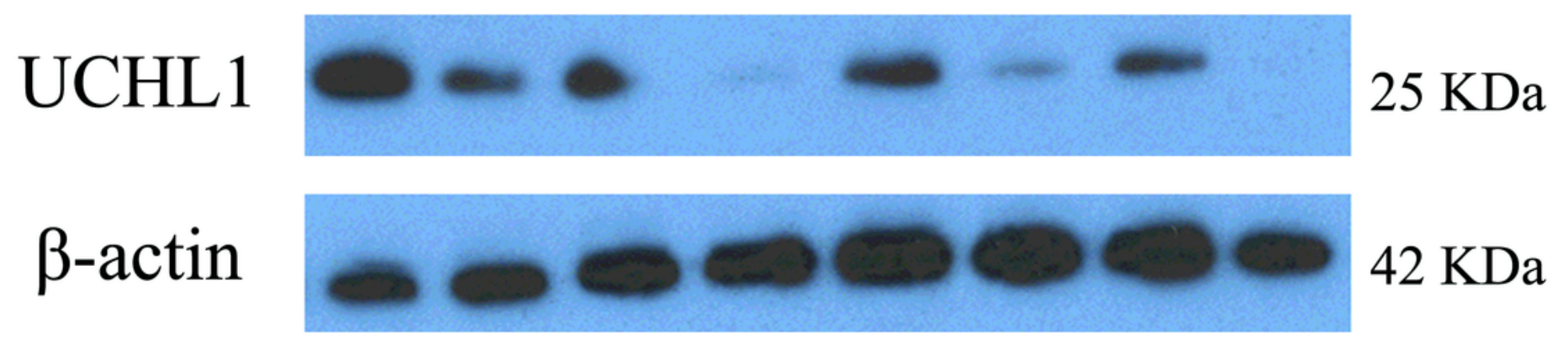

Figure 1

Analysis of UCHL1 expression in stage II colon cancer . (A) UCHL1 was significant up regulated in 96 stage II colon cancer tissues than in the matched non-cancerous mucosa, the logarithmic scale 2- $\triangle \triangle \mathrm{Ct}$ was used to represent the fold change in the qPCR analysis ( $* \star * P<0.001)$. (B) Western blotting confirmed that higher UCHL1 protein expression was observed in stage II colon cancer tissues than in the matched non-cancerous mucosa. 
A

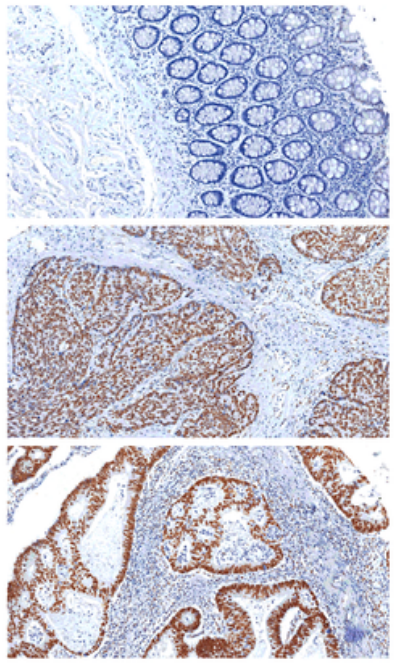

$\mathrm{B}$

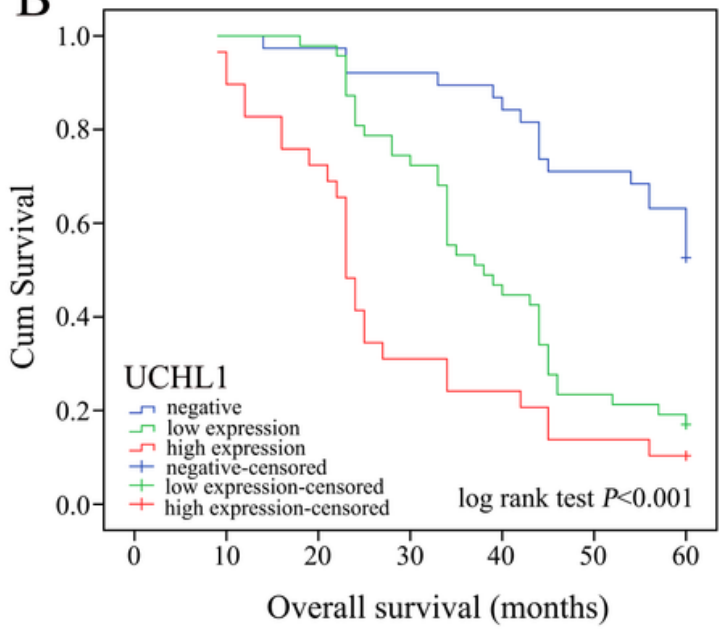

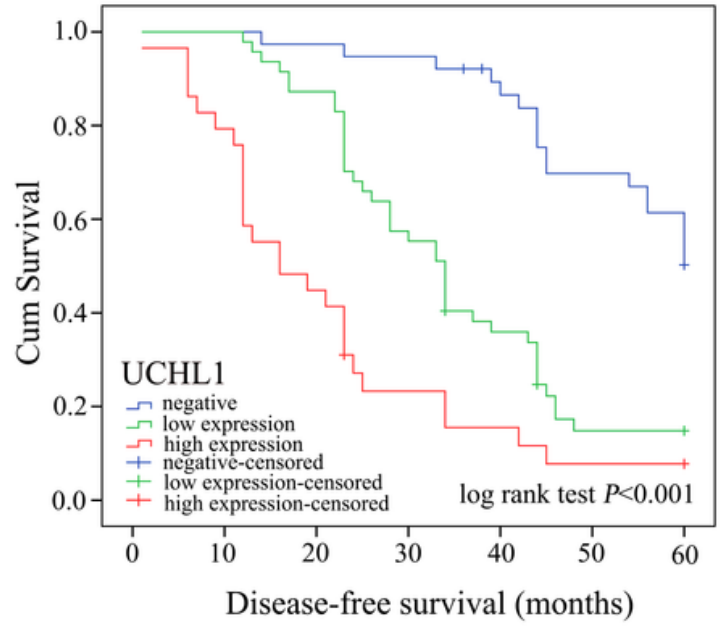

Figure 2

Kaplan-Meier curves with a log rank analysis for 114 stage II colon cancer patients who accepted 5-FU based chemotherapy after radical resection. (A) Immunohistochemical staining for UCHL1 expression in normal and colon cancer specimens. (Upper: normal mucosa. Middle and lower: poorly and moderately differentiated adenocarcinoma). (B) Kaplan-Meier survival curves for overall survival (left) and diseasefree survival(right) of stage II colon cancer patients who received 5-FU based adjuvant chemotherapy. Both the overall survival rate and disease-free survival rate of UCHL1-positive patients were significantly lower than that of the UCHL1-negative patients (log-rank test, $\mathrm{P}<0.001$ ). 

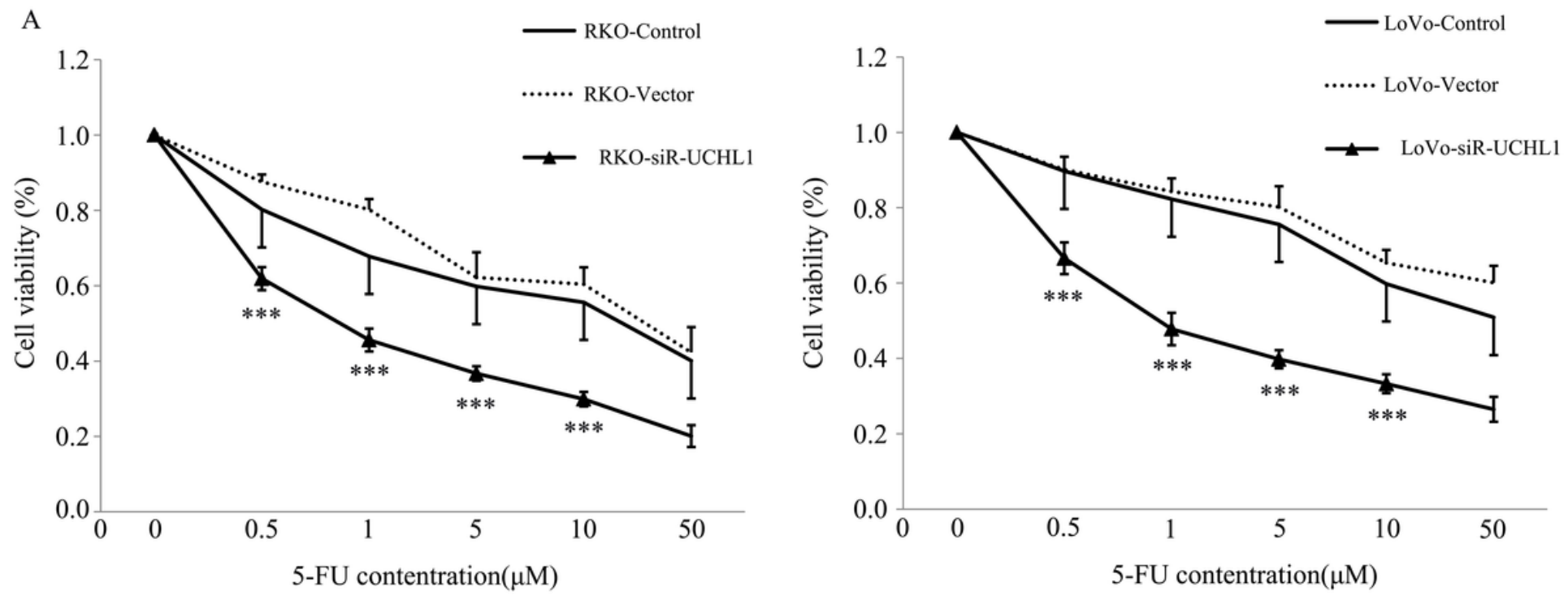

B
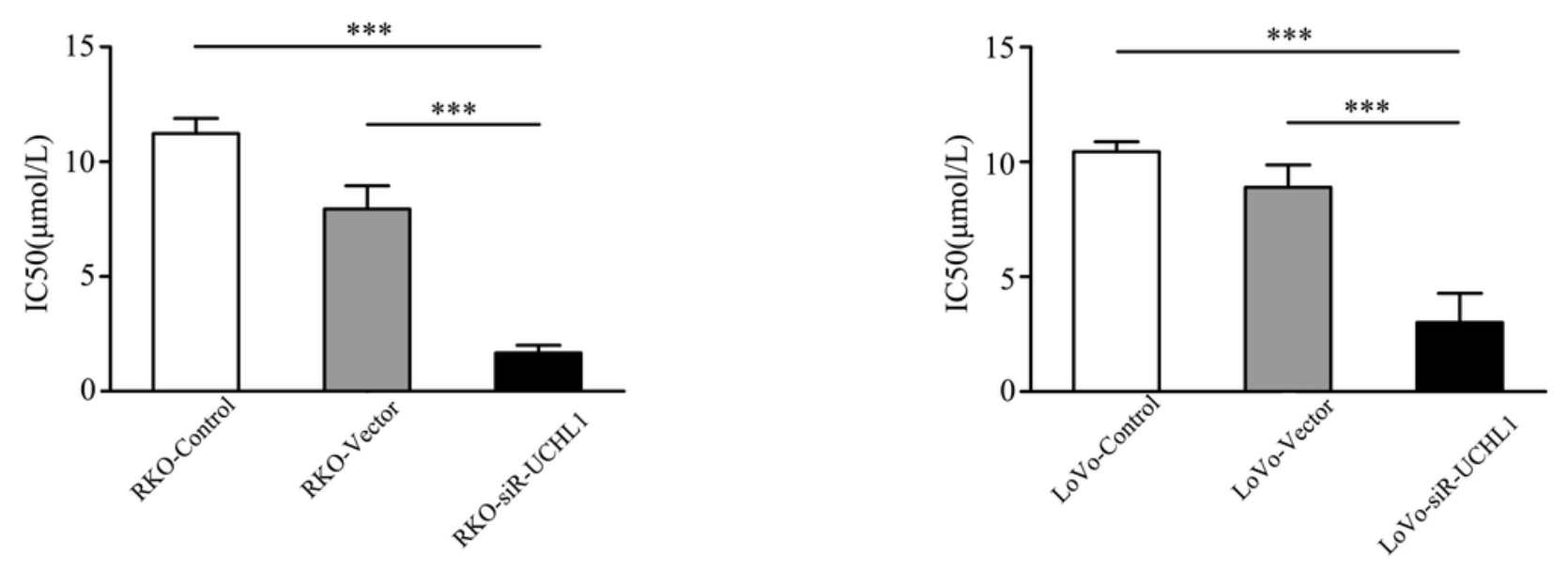

Figure 3

Down regulation of UCHL1 inhibited cell viability and chemoresistance in colon cancer cells. (A) Cell viability of RKO (left) and LoVo (right) in different 5-FU concentrations. (B) IC50 of RKO and LoVo in different 5-FU concentrations. The bars represent means \pm SEM. ${ }^{*} P<0.05,{ }^{*} * \mathrm{P}<0.001$. 
A
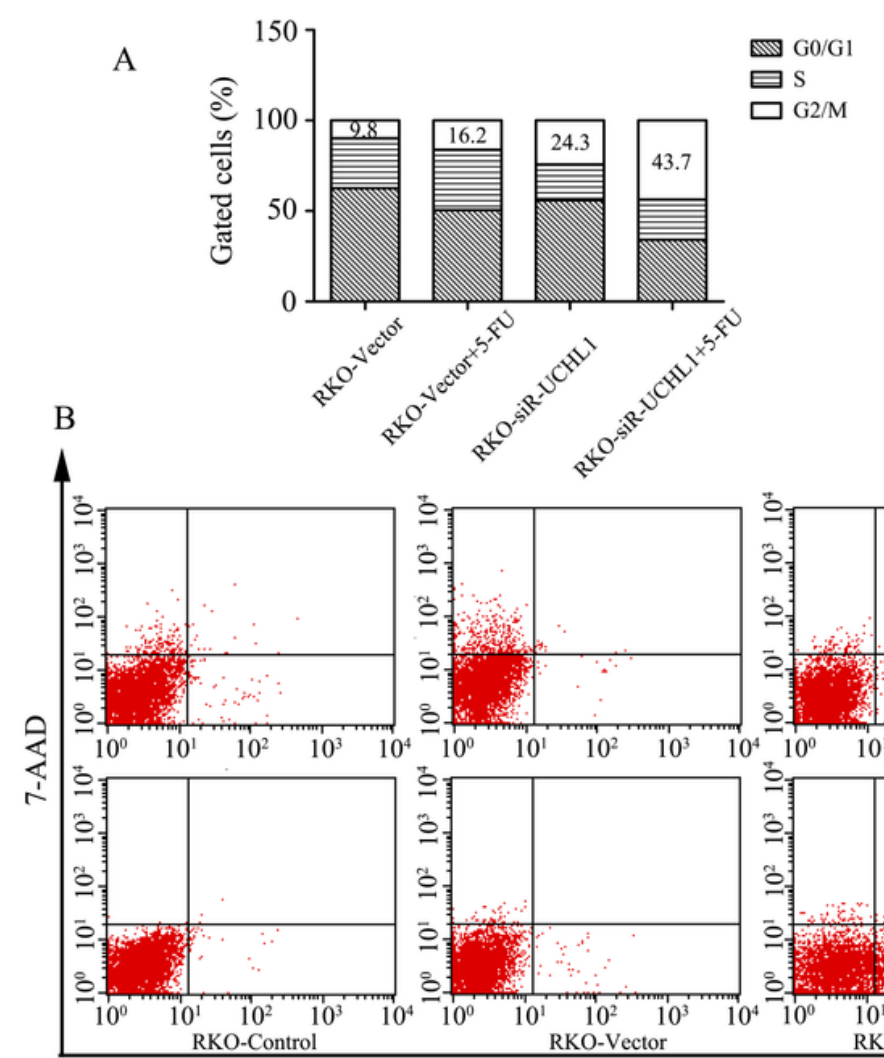

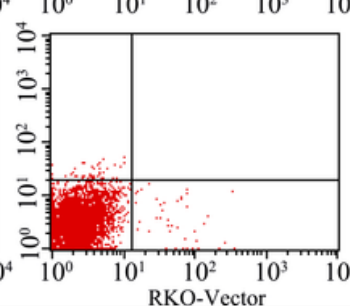

Annexin V-PE

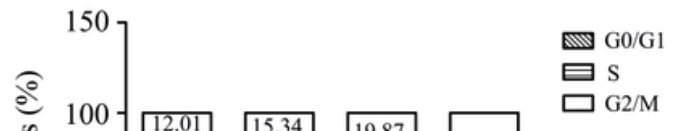

$\boxminus \mathrm{s}$

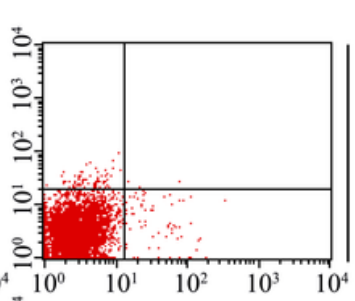

$\mathrm{C} \stackrel{2}{\circ}$

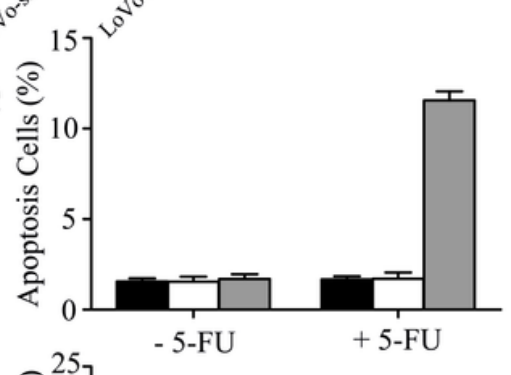

RKO-Control

$\square$ RKO-Vector

$\square$ RKO-siR-UCHLI
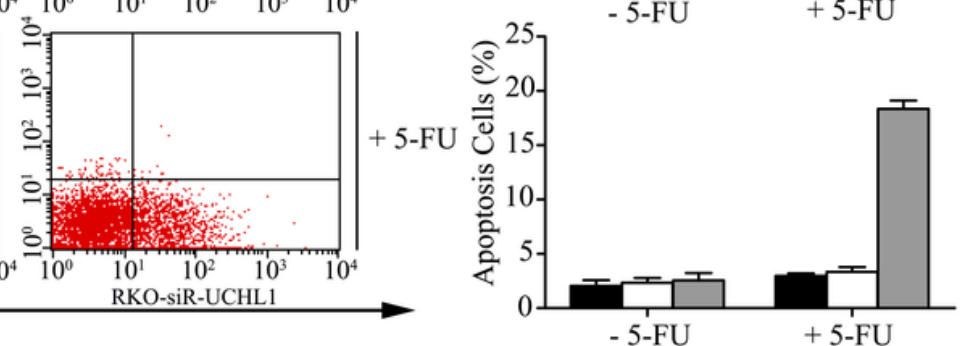

LoVo-Control $\square$ LoVo-Vector $\square$ LoVo-siR-UCHL

\section{Figure 4}

Down regulation of UCHL1 exhibit a greater degree of cell cycle arrest and apoptosis. (A) Down regulation of UCHL1 in RKO (left) and LoVo (right) cells leading to a significant increase in G2/M phase cell arrest. (B) Apoptosis in RKO and LoVo cells treated with 10 $\mu \mathrm{M}$ 5-FU for $48 \mathrm{~h}$ was clearly increased in siR-UCHL1 group. Data are given as mean \pm SD of three independent experiments. Statistical comparisons were made using two-tailed unpaired t-test. Representative illustrations are shown in (B, left). 


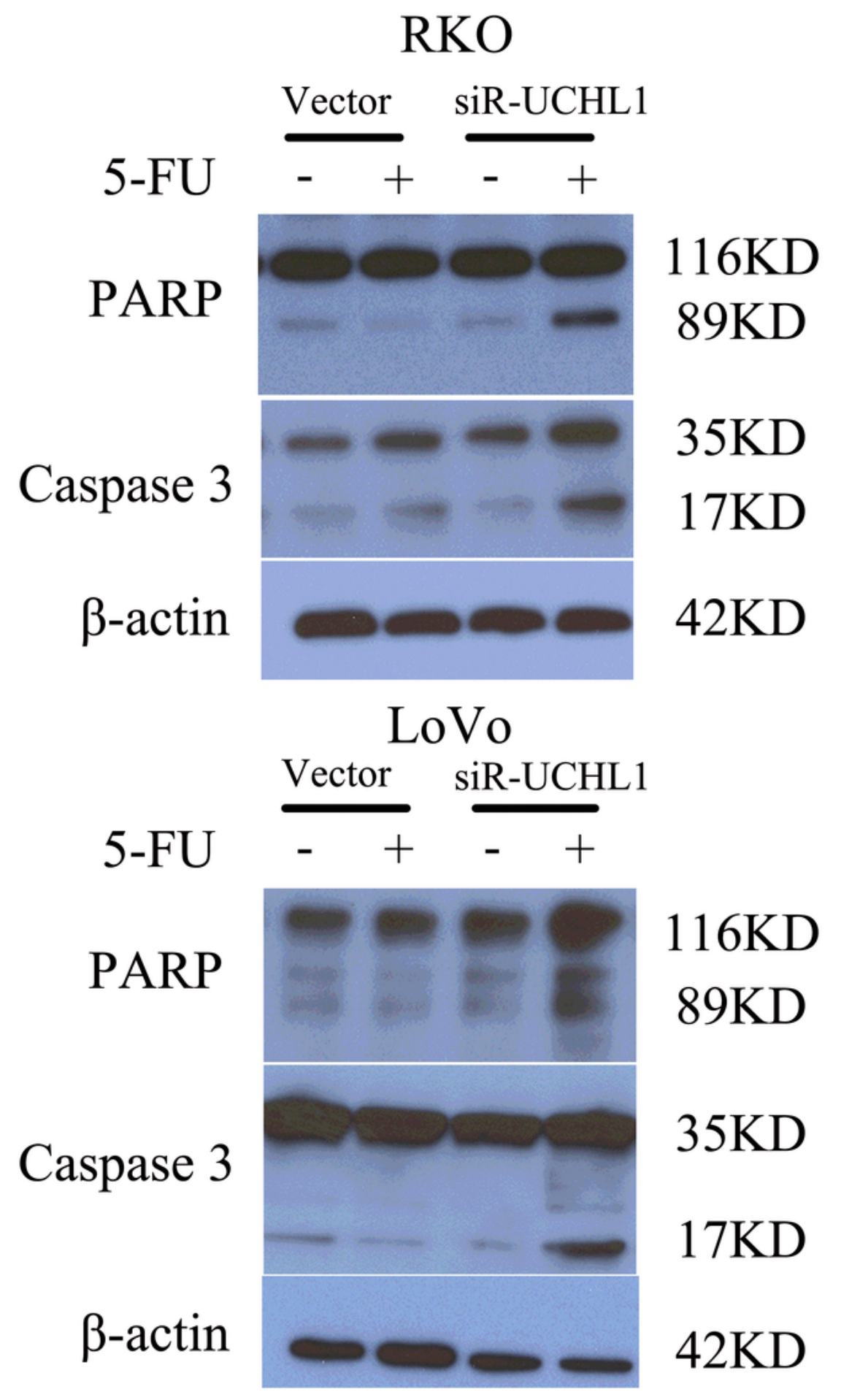

Figure 5

Expression status of apoptosis-related molecules after treatment with 5-FU. Western blotting analysis showed that caspase 3 and PARP were cleaved in siR-UCHL1 cells (Upper: RKO cell lines, Lower: LoVo cell lines) 


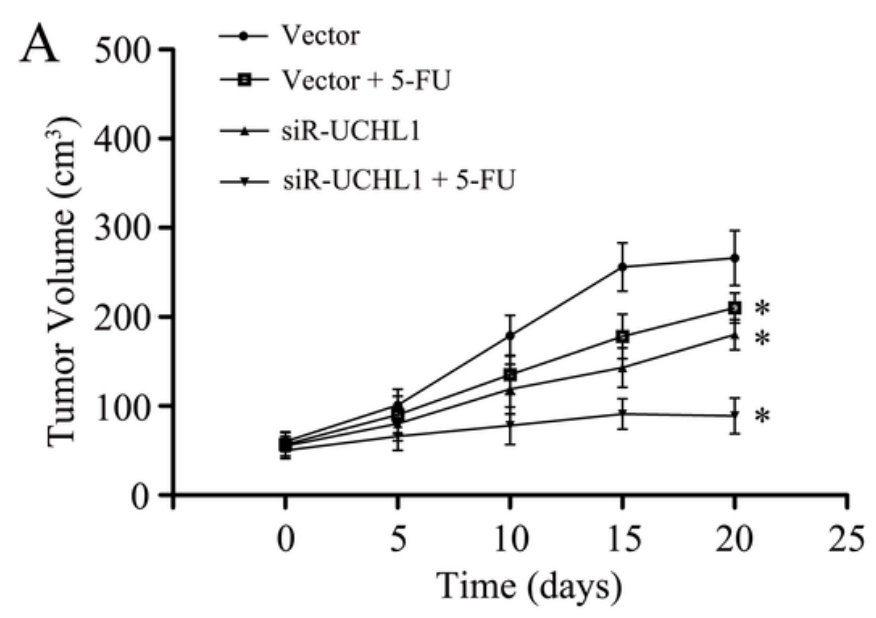

$\mathrm{C}$

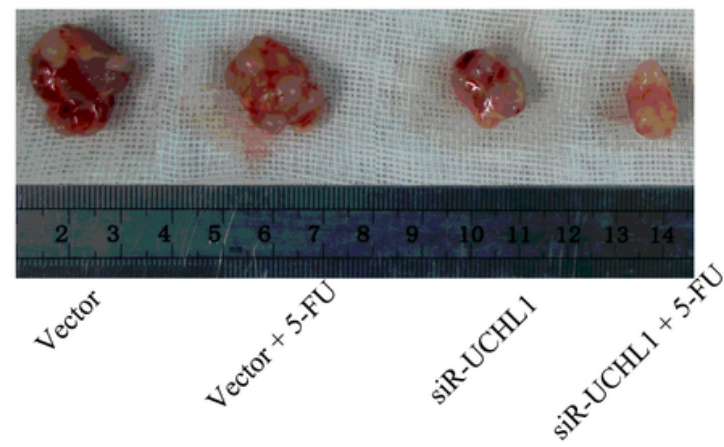

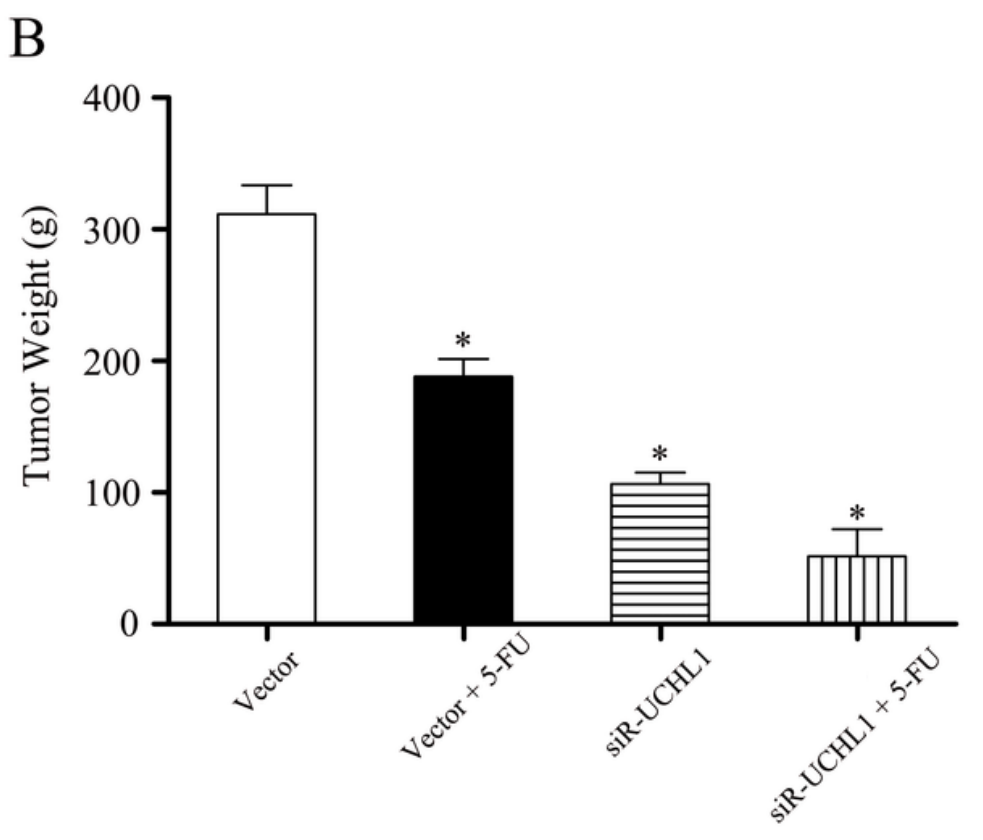

Figure 6

Down regulation of UCHL1 inhibit colon cancer growth and enhance 5-FU based chemotherapy sensitivity in vivo. (A) The tumor volume was calculated once 5 days. (B) All mice were euthanized and tumors were weighed. Data are expressed as mean \pm standard deviation. (C) siR-UCHL1 and control clones of RKO cells were injected subcutaneously into the flank of nude mice. 